\title{
Imagens de si e emoções em Stupeur et Tremblements, de Amelie Nothomb
}

\author{
Renata Aiala de Mello ${ }^{1}$
}

Resumo: Com este trabalho, visamos investigar a estrutura textual e discursiva de uma obra literária específica da escritora belga Amélie Nothomb, a saber, Stupeur et tremblements, publicada em 1999. Para a consecução desse objetivo, selecionamos, como área de conhecimento para o aporte teórico, a Análise do Discurso em suas interfaces com os estudos da Retórica. Nessa confluência, valemo-nos, sobretudo, de categorias analíticas tais como gênero, ethos, pathos e estereótipo. Com a ajuda desse instrumental, é possível discutir a problemática que envolve a obra, que é, ao mesmo tempo, considerada um romance, uma autobiografia ou até mesmo uma autoficção. Em gêneros como esses, o conceito de ethos torna-se importante, na medida em que a tônica da narrativa recai sobre as identidades da autora, da narradora e da personagem principal. Como qualquer enunciação literária, a obra de Nothomb busca tocar seu leitor. Por essa razão, o conceito de pathos auxilia nos estudos não só das emoções presentes na obra, mas também daquelas visadas no leitor instituído. Por fim, a noção de estereótipo, ligada a noções de saberes de crença e imaginários socio-discursivos, nos permite contextualizar mais e melhor a obra em seu espaço-tempo.

Palavras-chave: Amélie Nothomb, Stupeur et tremblements, imagem de si, emoções, Análise do Discurso.

\section{Introdução}

O título da obra de Nothomb - Stupeur et tremblements - já prenuncia sua temática: emoções fortes tais como estupor e tremor. Não é por acaso que a obra duplamente traduzida para o português traz como título palavras e sentimentos iguais ou semelhantes ao original:

\footnotetext{
${ }^{1}$ Universidade Federal da Bahia. Doutora em Estudos Linguísticos - Estudos do Texto e do Discurso pela Universidade Federal de Minas Gerais. Professora adjunta do Departamento de Letras Românicas do Instituto de Letras da Universidade Federal da Bahia.Email: demello.renata@gmail.com.
}

Gláuks: Revista de Letras e Artes - jan/jun. 2019 - Vol. 19, $N^{o} 1$ 
Temor e Tremor, na tradução de Carlos Sousa de Almeida (2000), e Medo e Submissão, na tradução de Clóvis Marques (2001).

No que diz respeito ao enredo da obra, temos o período de um ano que a narradorapersonagem viveu no Japão. Amélie narra essa sua experiência de vida no Oriente, registra suas histórias profissionais em uma empresa japonesa. Nesse contexto, com humor e ironia, a narradora reflete, por exemplo, sobre as relações sociais, a rígida hierarquia naquela empresa, enfim, sobre os costumes da cultura japonesa. Daí nosso intuito de resgatar na narrativa de Nothomb os elementos enunciativos, textuais e discursivos que denotem (e conotem) a construção da imagem identitária da narradora e das demais personagens que representariam o Oriente, além das emoções vividas pelas personagens e visadas pela obra para tocar os leitores instituídos.

Ainda que o livro tenha várias capas, a depender das edições, há alguns traços comuns que vão além do nome da autora e do título da obra. Na maioria, consta a palavra "romance ", que remete, evidentemente, à categoria genérica romance. No entanto, durante a leitura, percebemos um teor autobiográfico, o que remeteria a gêneros literários específicos e afins tais como romance autobiográfico, diário íntimo, mémorias, autoficção, autobiografia e história de vida, entre outros. Toda essa pluralidade leva-nos a pesquisar, ainda que superficialmente, o gênero ao qual essa publicação de Nothomb pertenceria, razão pela qual escolhemos discutir a categoria analítica de gênero. Como o conceito é amplo e complexo, restringimos o aporte teórico a alguns autores próximos de nossa linha de pesquisa: Bakthin (2010), Doubrovsky (1977), Grell (2014), Lejeune (1996) e Maingueneau (2001b).

As três provas retóricas aristotélicas presentes na narrativa subsidiam nossa análise do romance de Nothomb. Assim, as instâncias enunciativas de Stupeur et Tremblements constroem a imagem de si e têm, por princípio, querer tocar o outro. Este outro pode referir-se tanto às personagens presentes na narrativa, no nível interno da obra (intradiegese), quanto ao leitor, no nível externo (extradiegese). Os efeitos ethóticos e pathêmicos, por sua vez, estão ligados às representações e aos imaginários sociodiscursivos. Em Nothomb, percebemos que a imagem que ela forja do Oriente é sustentada por uma série de estereótipos historicamente cristalizados em oposição dicotômica com o Ocidente. A identidade cultural japonesa é narrativizada pela autora

Gláuks: Revista de Letras e Artes - jan/jun. 2019 - Vol. 19, $N^{o} 1$ 
de forma contrastiva com sua cultura europeia e eurocêntrica. Para entendermos essa visão particular, valemo-nos da obra de Said (2007) sobre o Oriente como uma invenção do Ocidente. Para nos subsidiar nas categorias de ethos, pathos, logos e estereótipo, selecionamos textos de Amossy (1984, 1991, 1999, 2010), Amossy \& Herscherberg Pierrot (2011), Charaudeau (1983, 2000, 2007, 2008); Maingueneau (2005, 2006, 2008, 2010) e Plantin (2011).

As opções pelos teóricos supracitados e as categorias de análise escolhidas para este trabalho se justificam por acreditarmos que nosso corpus aciona procedimentos particulares de construção da imagem de si e do outro e das emoções baseadas em estereótipos e em saberes de crença. Procedimentos que são de responsabilidade dos sujeitos envolvidos na interação, que se ancoram nos universos sociais e contextuais, ou seja, que se adaptam a liberdades e também a restrições, às possibilidades impostas/oferecidas, no nosso caso em análise, pela narrativa de Nothomb. Considerando a dimensão e a riqueza do universo nothombiano, as questões levantadas neste artigo não visam, evidentemente, esgotar sua abrangência. Ainda assim, esperamos que este trabalho funcione como um exercício de compreensão da estrutura e do funcionamento da obra Stupeur et tremblements.

\section{Fragmentos da vida e obra de Nothomb}

Para melhor compreender o funcionamento de Stupeur et tremblements, acreditamos ser importante passar em revista, ainda que superficialmente, a obra da autora e também um pouco de sua vida. Isso porque grande parte de seus romances têm forte ligação com suas experiências pessoais. Nothomb é uma mulher de seu tempo, é sobre ele que ela escreve sua obra e é na escritura que ela deixa suas marcas. Os romances Le sabotage amoureux (1993), Stupeur et tremblements (1999), Métaphysique des tubes (2000), Antéchrista (2003), Ni d'Eve ni d'Adam (2007), Une forme de vie (2010) e La nostalgie heureuse (2013) são considerados por alguns críticos como autoficcionais e, pela própria autora, como "histórias reais": “tout est vrai”, “c'est

Gláuks: Revista de Letras e Artes - jan/jun. 2019 - Vol. 19, $N^{o} 1$ 
une chose qui m'est arrivée"2, diz ela, frequentemente, em entrevistas (GRINFAS, 2007; LEE, 2004; SAGALYN, 2000; SAVIGNEAU, 2009).

Através de reportagens e entrevistas, Nothomb é frequentemente matéria de publicações na mídia. Entretanto, paradoxalmente, não se sabe muito sobre ela. Sabemos que seu nome de batismo é Fabienne Claire Nothomb, sendo Amélie Nothomb seu nom de plume. Segundo consultas biográficas e entrevistas dadas, Amélie Nothomb, filha de pai embaixador belga, nasceu provavelmente no Japão em 1966 e viveu até os cinco anos de idade no "país do sol nascente" até se mudar para a China, em seguida para Bangladesh e depois para os Estados Unidos, entre outros países em que seu pai manteve missões diplomáticas, até voltar para a Bélgica, aos dezessete anos, onde cursou Filologia Românica na Faculdade de Letras em Bruxelas e tornou-se escritora. Dizemos "provavelmente", porque mesmo sendo uma autora conhecida e midiatizada, há muitas informações divergentes sobre sua vida. Alguns estudiosos da autora afirmam, por exemplo, que ela nasceu na Bélgica e depois mudou-se para o Japão. Outros dizem que ela nasceu no Japão, mas tem origem belga. Há aqueles que dizem que ela nasceu em 1966, 1967 ou 1968.

No conjunto de sua obra, há recorrências temáticas: as difíceis relações interpessoais, seu interesse pela linguagem e pela comunicação, o que explicaria sua decisão de fazer Letras, a fascinação pelos defeitos grotescos das pessoas, sejam eles físicos ou morais, a devastação do corpo físico, o enigma e a perplexidade face ao ser humano. Esse conjunto de temas torna sua escrita singular, particular. (DAVID, 2006; LEE, 2004; SAGALYN, 2000)

Traduzido para mais de trinta idiomas, vencedor do prêmio do Grand Prix du roman de l'Académie Française em 2001, Stupeur et tremblements é o oitavo livro publicado por Amélie Nothomb. Diante do sucesso de venda, ele foi adaptado para o cinema em 2003, por Alain Corneau, e também para o teatro em 2014, pelas companhias Le Théâtre de Poche Montparnasse e La Compagnie de Théâtre des Hommes (LEE, 2004). Segundo a autora, um dos objetivos dessa publicação foi fazer uma crítica às hierarquias sociais, com "pitadas" de ironia e comicidade. Além disso, ainda segundo Nothomb, há, no texto, sentidos políticos sutis, tais como o relacionamento entre pessoas, a toxicidade da política, a relação entre o dominante e o dominado

\footnotetext{
${ }^{2}$ Tradução livre: "tudo é verdade”; "é uma coisa que aconteceu comigo".
} 
e um manual de como não se matar dentro de uma empresa. Entretanto, ela afirma não buscar se vingar do Japão, tampouco criar uma imagem negativa do seu país preferido. Para ela, há personagens que mostram a complexidade da cultura nipônica e suas diferenças com a ocidental:

[Il y a de] la beauté, oui ; et qui ne s'incarne pas seulement dans le personnage de Fubuki. Dans le système aussi, il y a une réelle beauté : dans l'égalitarisme social, par exemple, ou dans l'attitude des employés. Le système n'ouvre aucune possibilité de solidarité ; et pourtant elle s'exerce, au sein même de cette impossibilité, dans la scène du boycott. J'ai été choquée de lire que Stupeur et Tremblements était un livre de haine contre le Japon... Il y a seulement dans ce récit des personnages qui symbolisent la dualité du Japon : parfois répugnants, parfois magnifiques... ${ }^{3}$ (NOTHOMB apud GRINFAS, 2007)

Segundo Nothomb, sua experiência no Oriente foi muito difícil e ela precisou de quase dez anos para conseguir expressar aquilo que gostaria no romance Stupeur et tremblements. Em suas palavras, ela precisou superar as humilhações pelas quais passou e (re)construir uma imagem de si e uma maior clareza na representação do Oriente, antes de, instintiva e inconscientemente, registrar sua experiência no papel e narrativizar suas emoções.

\section{A problemática do gênero}

Em entrevista a Grinfas (2007), Nothomb fala do gênero ao qual Stupeur et tremblements pertence:

Stupeur est entièrement autobiographique. Mais je suis une romancière et, pour moi, il suffit qu'on raconte quelque chose en travaillant le style pour écrire un roman. Cette histoire m'est arrivée à $100 \%$ : j'ai seulement déguisé les noms de la compagnie et des personnages. ${ }^{4}$

\footnotetext{
${ }^{3}$ Tradução livre: [Há] beleza, sim; e que não é apenas representada na personagem de Fubuki. No sistema há também uma verdadeira beleza: no igualitarismo social, por exemplo, ou na atitude dos empregados. O sistema não permite nenhuma possibilidade de solidariedade; e ainda sim ela é exercida, mesmo dentro dessa impossibilidade, na cena do boicote. Fiquei chocada ao ler que Stupeur et tremblements era um livro sobre o ódio contra o Japão... Há apenas nesta narrativa personagens que simbolizam a dualidade do Japão: às vezes repugnantes, às vezes magnificos.

${ }^{4}$ Tradução livre: Stupeur et tremblements é inteiramente autobiográfico. Mas sou uma romancista e, para mim, basta contar alguma coisa com estilo para escrever um romance. Essa história aconteceu comigo integralmente (100\%): eu apenas mudei os nomes da companhia e das personagens.
}

Gláuks: Revista de Letras e Artes - jan/jun. 2019 - Vol. 19, $N^{o} 1$ 
Esse enunciado de Nothomb esclarece e confunde. Esclarece, no sentido de que ela própria classifica seu texto como autobiográfico. Confunde, porque ela não diferencia autobiografia de romance. Aliás, ela define o gênero romance de forma extremamente ampla; basta haver estilo e se auto-intitular romancista, para que se tenha um romance. No entendimento da romancista, é preciso narrar integralmente a verdade do vivido, para que o texto seja considerado autobiografia. Além disso, seu enunciado prevê que o fato de dizer que viveu $100 \%$ de tudo aquilo que narrou tornou, necessária e automaticamente, sua narrativa em romance e em autobiografia.

Sabemos, com Bakhtin (2010), que os gêneros surgiram, muito provavelmente, com as línguas, a linguagem, os discursos e os textos, razão pela qual eles são tão variados quanto as esferas da atividade humana. A problemática que envolve gênero faz com que vários elementos venham orbitar essa noção: forma composicional, marcas linguísticas, contexto, finalidade, estilo, conteúdo, tema, funcionamento, sujeitos da enunciação, entre outros fatores determinantes. Tudo isso ajuda a polemizar a noção de gênero e faz com que, muitas vezes, a discussão recaia sobre uma terminologia tipológica de classificação. No caso da Literatura, gênero secundário, na concepção de Bakhtin, tem-se tipos relativamente estáveis de textos, com traços em comum, que facilitam sua compreensão e sua classificação.

Segundo Maingueneau (2001a, 2001b), mesmo tendo sido retomada desde os anos de 1980, a noção de gênero permanece particularmente problemática, já que o texto excede toda determinação. Além disso, no caso do gênero literário, o leitor não tem contato com o gênero, mas sim com textos pertencentes a gêneros particulares, os quais só poderiam ser definidos se postos em relação com seus contextos sócio-históricos. Mesmo sendo um elemento periférico, uma questão de embalagem, o gênero não é exterior ao texto, mas, em vez disso, uma de suas condições. Dizer que um texto literário pertence ao gênero romance e/ou autobiográfico é, apesar do conjunto de elementos estruturantes que o compõe, algo bastante restritivo e delimitador. Se pensarmos na multiplicidade, na pluralidade e na heterogeneidade de textos tidos como literários ao longo do tempo, temos "para dar um exemplo extremo, não são os mesmos fatores de coerência que regem um poema surrealista, um sermão do século XIX e um drama romântico”.

Gláuks: Revista de Letras e Artes - jan/jun. 2019 - Vol. 19, $N^{o} 1$ 
(MAIGUENEAU, 2001b, p. 158)

Para Lejeune (1996), a autobiografia é uma narrativa retrospectiva em prosa que uma pessoa real faz de sua própria existência, no momento em que ela dá ênfase à sua vida individual, mais particularmente, à história de sua personalidade. Ainda que delimitadora, essa definição é ampla e abarca uma vasta quantidade de textos. Condições de genericidade tais como tratar, em forma de prosa, da vida individual e pregressa de uma personalidade real (a do próprio autor) e haver coincidência entre autor, narrador e personagem, não nos parece suficientes para categorizar um texto de autobiográfico. Ainda segundo Lejeune (1996), caso algumas dessas características da autobiografia esteja ausente, tem-se outros gêneros como memórias, biografia, romance pessoal, poema autobiográfico, diário íntimo, autorretrato e ensaio.

Doubrovsky propõe uma visão outra a respeito de gêneros literários que englobam histórias de vida. No prefácio de sua obra Fils (1977), o autor assevera que:

\begin{abstract}
Autobiographie ? Non, c'est un privilège réservé aux importants de ce monde, au soir de leur vie, et dans un beau style. Fiction, d'évènements et de faits strictement réels ; si l'on veut, autofiction, d'avoir confié le langage d'une aventure à l'aventure du langage, hors sagesse et hors syntaxe du roman, traditionnel ou nouveau. Rencontres, fils de mots, allitérations, assonances, dissonances, écriture d'avant ou d'après littérature, concrète, comme on dit musique. Ou encore, autofriction, patiemment onaniste, qui espère faire maintenant partager son plaisir. (DOUBROVSKY, 1977, p. 10 - grifos do autor) ${ }^{5}$
\end{abstract}

A partir desse excerto, percebemos que Doubrovsky, Lejeune e Nothomb trabalham com elementos parecidos ou próximos para definir alguns gêneros literários. Os três veem a autobiografia como um gênero particular, no qual o autor se volta para o seu passado para narrar, em prosa, fatos reais vividos por ele. No entanto, para Doubrovsky, para se ter uma autobiografia, é condição que seu autor seja uma personalidade socialmente reconhecida e já tenha vivido boa parte da sua vida para poder falar sobre ela. Esse não é o caso, por exemplo, de Nothomb, que, apesar de ser considerada por muitos uma personalidade, escreveu Stupeur et tremblements, aos 32 anos de idade aproximadamente. Tanto para Doubrovsky quanto para Nothomb, é preciso que

\footnotetext{
${ }^{5}$ Tradução livre: Autobiografia? Não, esse é um privilégio reservado aos importantes desse mundo, ao fim de suas vidas, e em belo estilo. Ficção, de acontecimentos e fatos estritamente reais; se se quiser, autoficção, por ter confiado a linguagem de uma aventura à aventura da linguagem, fora da sabedoria e fora da sintaxe do romance, tradicional ou novo. Encontro, fios de palavras, aliterações, assonâncias, dissonâncias, escrita de antes ou de depois da literatura, concreta, como se dizem música. Ou ainda: autofricção, pacientemente, onanista, que espera agora compartilhar seu prazer.
}

Gláuks: Revista de Letras e Artes - jan/jun. 2019 - Vol. 19, $N^{\circ} 1$ 
o estilo da escrita seja bem cuidado, considerado "belo". Enquanto Nothomb não vê de forma estaque as diferenças entre um romance e uma autobiografia, Doubrovsky vê um terceiro gênero: a autoficção. Essa noção forjada por Doubrovsky traz uma nova composição de elementos constitutivos de gênero. Não precisa ser famoso e tampouco idoso; com mais liberdade, misturase realidade, fatos, verdade e ficcionalidade. Assim, se seguirmos o entendimento de Lejeune, Stupeur et tremblements seria uma autobiografia e, se seguirmos o entendimento o de Doubrovsky, seria uma autoficção.

Finalizando essa discussão que não se fecha, valemo-nos do trabalho de Grell (2014) sobre autoficção, a partir do entendimento de Doubrovsky. Segundo a autora, autoficção complexifica ainda mais a problemática entre romance e autobiografia, pois essa noção vai além de simplesmente propor junções entre gêneros. A estudiosa destaca que não há razão para separações estanques entre realidade e ficção, sinceridade e mentira, podendo todos esses elementos se completarem e se complementarem. Essa visão alargada de Doubrovsky e de Grell nos permite um olhar menos cerceador da obra de Nothomb, ou seja, ela é real e também ficcional; ela representa $100 \%$ do vivido, mas é, ainda sim, representação; essa ambiguidade faz parte de sua essência. Há, nessa discussão, questões importantes a respeito da subjetividade, da (i)legalidade e da (des)igualdade entre o vivido e o narrado. Por fim, a noção de autoficção joga luz na questão da identidade daquele que narra sobre sua vida, da autoria, da autorialidade, enfim, do autor e de sua morte, tanto no sentido foucaultiano quanto barthesiano.

\section{O Ethos em Amélie}

Nos interessa analisar a imagem identitária da autora e seus desdobramentos nas instâncias enunciativas da narradora e personagem. Para tanto, valemo-nos do conceito de ethos $^{6}$, visto que

\footnotetext{
${ }^{6}$ Tomamos, aqui, os enunciados ethos, imagem de si e imagem identitária como sinônimos.
}

Gláuks: Revista de Letras e Artes - jan/jun. 2019 - Vol. 19, $N^{o} 1$ 
ele possibilita observar a maneira pela qual Nothomb arquiteta discursivamente sua imagem diante do leitor.

No entendimento de Maingueneau (2008), ethos é fundamentalmente um processo interativo, produzido em situações comunicativas específicas, não correspondendo, necessariamente, à imagem do locutor exterior à sua fala, à sua moral, seu caráter. Entretanto, o autor alerta que, para trabalhar com a noção de ethos, é preciso realizar um duplo deslocamento: (i) afastar-se de preocupações psicologizantes e voluntaristas no trato das instâncias enunciativas; (ii) levar em conta a transversalidade da noção de ethos em relação aos discursos/textos tanto orais quanto escritos. Nesse sentido, não se pode ver o ethos como uma representação estática e tampouco (de)limitada do sujeito. Ele se constitui de forma dinâmica, cambiante, construído no e pelo discurso e em co-participação com o destinatário. A noção de ethos

[...] foi retomada em ciências da linguagem e, principalmente, em análise do discurso, em que se refere às modalidades verbais da apresentação de si na interação verbal. [...] O 'ethos' faz parte, como o 'logos' e o 'pathos', da trilogia aristotélica dos meios de prova. [...] Adquire em Aristóteles um duplo sentido: por um lado, designa as virtudes morais que garantem credibilidade ao orador, tais como a prudência, a virtude e a benevolência [...]; por outro, comporta uma dimensão social, na medida em que o orador convence ao se exprimir de modo apropriado a seu caráter e a seu tipo social [...]. Nos dois casos, trata-se da imagem de si que o orador produz em seu discurso, e não de sua pessoa real. (CHARAUDEAU \& MAINGUENEAU, 2004, p. 220)

Isso posto, temos, em Stupeur et tremblements, um compósito de vozes enunciativas (autora-narradora-personagem) que convergem para Amélie Nothomb. Antes mesmo de iniciarmos a leitura do romance, já é possível uma co-construção ethótica prévia dessas instâncias através da capa do livro. Em grande parte das edições desse romance, consta, na capa, a fotografia da autora, maquiada como uma gueixa. Além da fotografia, na capa tem-se o nome Amélie Nothomb. Esses elementos ajudam a elaborar uma imagem tanto da autora quanto da obra. Vale (re)lembrar que, em várias edições, tem-se o enunciado "romance", o que também auxilia nessa construção.

Além do primeiro contato proposto pela capa, há uma gama de informações exteriores à obra disponível para o leitor. Nothomb é internacionalmente (re)conhecida, matéria de diversos artigos de jornais e revistas, enfim, uma personalidade mediatizada. Ao relatar, em suas

Gláuks: Revista de Letras e Artes - jan/jun. 2019 - Vol. 19, $N^{o} 1$ 
entrevistas, por exemplo, suas experiências no Japão, a autora está forçosamente construindo seu ethos. Quando ela diz “J'ai compris, à 20 ans, pourquoi le Japon était mon pays" (NOTHOMB apud AHL, 2013), "Stupeur et tremblements est le récit a posteriori d'une Japonaise ratée..." (NOTHOMB apud GRINFAS, 2007), ou ainda "Je suis belge et j'entends bien le rester"' (NOTHOMB apud JOWA \& MERTENS, 2001), a autora está atualizando e presentificando a imagem de si diante de seus leitores. No entanto, mesmo que ela não dissesse explicitamente "eu sou isso", "eu não sou aquilo" (BARTHES, 1975, p. 203), o simples fato de sabermos que ela é mulher, jovem, romancista, entre várias outras informações colhidas, é suficiente para imaginar quem ela é, o que ela faz, e até mesmo o que ela narra em Stupeur et tremblements. Essas informações previamente coletadas e a veracidade dos fatos serão, no momento da leitura do livro, confirmadas ou refutadas pelo leitor, que, na condição de co-enunciador, é também responsável por essa imagem ethótica capaz de abarcar tanto a autora, a narradora-personagem, quanto a própria obra.

Já nas primeiras frases de Stupeur et tremblements, na descrição de sua chegada na empresa, temos mais alguns elementos delineadores de seu ethos:

\begin{abstract}
Monsieur Haneda était le supérieur de monsieur Omochi, qui était le supérieur de mademoiselle Mori, qui était ma supérieure. Et moi, je n'étais la supérieure de personne. On pourrait dire les choses autrement. J'étais aux ordres de mademoiselle Mori, qui était aux ordres de monsieur Saito, et ainsi de suite [...] donc, j'étais aux ordres de tout le monde. (NOTHOMB, 1999, p. 7)
\end{abstract}

De forma irônica, a narradora-personagem diz quem é, o lugar que ocupa naquela sociedade, vista como fortemente hierarquizada. Em uma espécie de dicotomia, ela acaba, então, por também forjar, ou melhor, presentificar e cristalizar a representação identitária dos orientais aos olhos do Ocidente.

\footnotetext{
${ }^{7}$ Tradução livre: "Eu entendi, aos 20 anos, porque o Japão era meu país."; "Stupeur et tremblements é a narrativa a posteriori de uma japonesa fracassada..."; "Eu sou belga e pretendo permanecer assim".

${ }^{8}$ O Sr. Haneda era o superior do Sr. Omochi, que era o superior do Sr. Saito, que era o superior da Srta. Mori, que era minha superiora. E eu não era superior de ninguém. Poderíamos colocar as coisas de outra maneira. Eu estava às ordens da Srta Mori, que estava às ordens do Sr. Saito e assim por diante [...] portanto, eu estava às ordens de todos. (NOTHOMB, 2001, p. 5 Tradução de Clóvis Marques)
}

Gláuks: Revista de Letras e Artes - jan/jun. 2019 - Vol. 19, $N^{o} 1$ 
Em um outro episódio, quando vai realizar sua primeira atividade na empresa, Amélie precisa responder a um e-mail. Uma tarefa aparentemente simples, torna-se um suplício, visto que seu superior, sempre insatisfeito com o trabalho de Amélie, rasga suas mensagens, obrigando-a a refazer várias vezes. Assim, a cada episódio narrado, o ethos de Amélie vai se construindo, de maneira distinta, tanto para os que com ela trabalham, que a veem, no nível intradiegético, como uma ocidental ignorante e incompetente, quanto para nós, leitores ocidentais, que no nível extradiegético, que a vemos como uma artista sensível e competente. Ainda nos dois níveis, temos a questão da aparência física e do domínio da língua japonesa impactando nesses ethé de Amélie. Para os que trabalham com ela na empresa, a personagem é, e sempre será, uma estrangeira que, apesar de dominar a língua japonesa, desconhece os hábitos e costumes desse povo. Já para seus leitores, Amélie viveu experiências humilhantes e traumatizantes narradas de forma bem-humorada, o que reforça positivamente seu ethos.

Em outro momento, temos que a narradora serve chá para os convidados da empresa. Ao mostrar que ela, uma branca, ocidental, domina perfeitamente tanto o idioma japonês quanto o ritual do chá, os presentes, segundo a narradora, se sentem extremamente desconfortáveis com a cena:

Ce fut alors qu'il m'appela, sur un ton furieux. Je le suivis jusqu'à un bureau vide. Il me parla avec une colère qui le rendait bègue : - Vous avez profondément indisposé la délégation de la firme amie ! Vous avez servi le café avec des formules qui suggéraient que vous parliez le japonais à la perfection. [...] Vous avez créé une ambiance exécrable dans la réunion de ce matin : comment nos partenaires auraient-ils pu se sentir en confiance avec une Blanche qui comprenait leur langue ? A partir de maintenant, vous ne parlez plus japonais. (NOTHOMB, 1999, p. 20) ${ }^{9}$

A cada "erro" de comportamento cometido, Amélie vai sendo rebaixada nas funções dentro da empresa e, concomitantemente, elevada na empatia para com seus leitores. Do cargo de intérprete e tradutora de francês-japonês, em um ano, ela passa por contabilidade, atualizadora de calendários, servidora de chá, auxiliar de copiadora, para finalizar como madame pipi

\footnotetext{
${ }^{9}$ Foi então que ele me chamou, em tom furioso. Segui-o até um gabinete vazio. Ele me falou com uma cólera que o fazia gaguejar: - A senhora afrontou seriamente a delegação da firma amiga! Serviu o café com fórmulas que davam a entender que falava o japonês à perfeição. [...] A senhora criou um clima execrável na reunião desta manhã: como haveriam nossos parceiros de sentir-se à vontade com uma branca que entendia sua língua? A partir de agora, a senhora não fala mais japonês. (NOTHOMB, 2001, p. 15 - Tradução de Clóvis Marques)
}

Gláuks: Revista de Letras e Artes - jan/jun. 2019 - Vol. 19, $N^{o} 1$ 
(NOTHOMB, 1999, p. 132), ou seja, limpadora de banheiro e, vale acrescentar, do banheiro masculino. A narrativa tem, nesse sentido, a função de ligar dois universos que convergem para a vida e a obra de Nothomb. Seu romance autoficcional atualiza sua história de vida e espetaculariza, por um lado, as várias imagens de si e, por outro lado, a representação do Oriente.

\section{O Pathos em stupeur et tremblements}

Há uma grande e dupla recorrência de pathemizações em Stupeur et tremblements. No nível intradiegético, elas se dão sobretudo nas temáticas relativas ao trabalho e nas relações sociais vivenciadas pela narradora-personagem. No nível extradiegético, percebemos, já no título da obra, a presença e a força da pathemização. O título e a temática do romance tornam-se, nesse sentido, estratégias discursivas utilizadas pela autora para tocar, seduzir e aguçar a curiosidade de seu leitor. Ela provoca a adesão passional do leitor atingindo suas pulsões emocionais.

Quando analisamos as emoções em Nothomb, não podemos e não devemos considerar reações tais como cólera, medo, vergonha ou alegria, sob o viés da Psicologia (CHARAUDEAU, 2000). Por se tratar de uma pesquisa em Linguística, com viés na Retórica, só podemos considerar as emoções em um quadro teórico discursivo que permita descrevê-las em moldes enunciativos, ou seja, observar como ela é construída pelas operações linguístico-discursivas, fundamentadas em topoi reconhecidos como válidos e eficazes na condução da argumentação para uma determinada direção.

A teorização sobre as emoções não é algo novo. Aristóteles, no que diz respeito ao $\operatorname{pathos}^{10}$, já afirmava que "as emoções são as causas que fazem alterar os seres humanos e introduzem mudanças nos seus juízos, na medida em que elas comportam dor e prazer: tais são a ira, a compaixão, o medo e outras semelhantes, assim como as suas contrárias” (2005, p. 160). Em estudo mais recente, Elster (1995) define, em linhas gerais, que as emoções e suas expressões

\footnotetext{
${ }^{10}$ Tomamos, aqui, os enunciados pathos, emoções e sentimentos como sinônimos.
}

Gláuks: Revista de Letras e Artes - jan/jun. 2019 - Vol. 19, $N^{o} 1$ 
são subjetivas e reguladas pelas normas sociais partilhadas e sustentadas, seja para sua aprovação ou desaprovação. Assim, as emoções discursivizadas se dão sempre a propósito de alguma coisa; elas têm um objetivo ou um alvo intencional. As emoções devem ser vistas como algo que vai além das simples sensações e pulsões. As emoções, além de estarem associadas a informações e a conhecimentos que alguém possui, advêm de uma espécie de julgamento subjetivo atrelado aos saberes de crença compartilhados.

Isso posto, tanto Nothomb-escritora, no mundo empírico, quanto Nothomb-narradora/personagem, no universo ficcional, discursivizam suas emoções conforme suas pretensões, suas visadas. Essas instâncias enunciativas articulam as emoções a outros acontecimentos e a outros sentimentos que circulam nos espaços sociais. Além disso, elas relacionam essas pretensões às memórias individuais e coletivas para escolherem estratégias que julgam mais pertinentes visando alcançar suas finalidades junto aos sujeitos interpretantes, sejam eles leitores ou personagens.

Com o subsídio desse aporte teórico, analisamos um cenário rico em pathemias. Trata-se do momento em que Fubuki é humilhada pelo seu superior Omochi diante de todos os colegas de trabalho. Essa cena parecia, segundo palavras da própria narradora, um estupro, tamanha a excitação do agressor em fazer sofrer, não por acaso, a única mulher da Yumimoto, além de Amélie. A narradora-personagem, muito constrangida diante dessa situação, resolve prestar solidariedade à sua colega desmoralizada no toalete feminino da empresa. A narradora desconhecia, até então, a gravidade do seu ato. Fubuki se volta contra Amélie com

[...] son regard éberlué de colère. Sa voix, méconnaissable de fureur pathologique, me rugit : - Comment osez-vous ? Comment osez-vous ? [...] Au paroxysme de la haine, elle rejeta mon bras comme un tourniquet et cria : - Voulez-vous vous taire ? Voulezvous partir ? [...] Elle marcha vers moi, avec Hiroshima dans l'œil droit et Nagasaki dans l'œil gauche. J'ai eu une certitude : c'est que si elle avait le droit de me tuer, elle n'eût pas hésité. (NOTHOMB, 1999, p. 125-126) ${ }^{11}$

Vemos, com essa cena, que a solidariedade é uma questão cultural e que pode, por essa razão,

\footnotetext{
${ }^{11}$ [...] seu olhar transtornado de cólera voltou-se para mim. Irreconhecível num furor patológico, sua voz rosnou para mim: Como ousa?! Como ousa!? [...] No auge do ódio, ela afastou meu braço e gritou: - Quer fazer o favor de se calar?! Quer sair daqui?! [...] Ela caminhou em minha direção, com Hiroxima no olho direito e Nagasaki no esquerdo. Uma certeza eu tenho: se ela tivesse o direito de me matar, não teria hesitado. (NOTHOMB, 2001, p. 93-94 - Tradução de Clóvis Marques)
}

Gláuks: Revista de Letras e Artes - jan/jun. 2019 - Vol. 19, $N^{o} 1$ 
provocar diferentes reações emocionais e discursivas. Tal ação dispara gatilhos extremamente negativos, visto que, na cultura japonesa, mostrar-se condoído com a humilhação pública de uma pessoa é humilhá-la ainda mais. Para Fubuki, e, por analogia, para os nipônicos, o que Amélie fez foi assistir e desfrutar o sofrimento do outro. Diferentemente, no Ocidente, não reagimos da mesma maneira ao presenciar uma pessoa que se afasta para sofrer e chorar no privado. Confortar alguém humilhado é quase que uma exigência social; prestar solidariedade é uma atitude afável. Nesse sentido, um leitor ocidental, muito provavelmente, vai se identificar com Amélie e se indignar com Fubuki, criando empatia com a primeira e antipatia com a segunda. Já um leitor oriental, possivelmente se solidarizaria com a japonesa, que foi duplamente humilhada.

Ao final do romance, a narradora justifica o título da obra:

Dans l'ancien protocole impérial nippon, il est stipulé que l'on s'adressera à l'Empereur avec "stupeur et tremblements". J'ai toujours adoré cette formule qui correspond si bien au jeu des acteurs dans les films de samouraïs, quand ils s'adressent à leur chef, la voix traumatisée par un respect surhumain. [...] (NOTHOMB, 1999, p. 172) $)^{12}$

Sobre o medo (temor, stupeur) uma das pathemias que dá nome à obra de Nothomb, Aristóteles (2005, p. 174) afirma que:

[...] o medo consiste numa situação aflitiva ou numa perturbação causada pela representação de um mal iminente, ruinoso ou penoso. Nem tudo o que é mal se receia [...], mas só os males que podem causar mágoas profundas ou destruições. [...] os males demasiado distantes não nos metem medo. Se o temor é isto, forçoso é admitir que as coisas temíveis são as que parecem ter um enorme poder de destruir [...] O que tememos são o ódio e a ira de quem tem o poder de fazer mal [...] tememos a injustiça que dispõe desse mesmo poder [...] os que podem cometer injustiça são temidos pelos que podem ser vítimas dela $[\ldots]$

Trazendo o que diz Aristóteles sobre a emoção do medo para o romance, podemos afirmar que há uma série de exigências dos japoneses em relação ao comportamento social. Há uma série de regras estritas a serem seguidas na empresa e pouca tolerância ao não cumprimento dessas. Esse rigor nas relações sociais pode provocar medo, pânico naqueles que não conhecem e não

\footnotetext{
${ }^{12}$ No antigo protocolo imperial nipônico, estipula-se que se haverá de dirigir a palavra ao Imperador com 'estupor e estremecimento'. Eu sempre adorei esta regra, que tão bem corresponde ao jogo dos atores nos filmes de samurais, quando se dirigem ao chefe, a voz traumatizada por respeito sobre-humano. [...]. (NOTHOMB, 2001, p. 130 - Tradução de Clóvis Marques)
}

Gláuks: Revista de Letras e Artes - jan/jun. 2019 - Vol. 19, $N^{o} 1$ 
dominam a língua e a cultura japonesa.

Tendo em vista a valorização da hierarquia pela sociedade nipônica, a personagem Amélie narra aquilo que ela sente em relação à essa hierarquia, tida como extremamente codificada, complexa e de difícil compreensão para o Ocidente. Ali, ela não teme ou estremece face ao imperador, mas sim, face a sua superiora direta, a senhorita Mori. Por analogia, percebemos que Amélie comporta-se (ou deveria se comportar) diante da senhorita Mori assim como os japoneses se comportam diante do imperador: "Je pris donc le masque de la stupeur et je commençai à trembler. Je plongeai un regard plein d'effroi dans celui de la jeune femme et je bégayai [...]" $\left(\right.$ NOTHOMB, 1999, p. 172) ${ }^{13}$. Nothomb parece querer mostrar aos leitores algumas emoções vividas pelos japoneses no cotidiano em contraste com aquelas possivelmente pelos seus leitores ocidentais diante das situações narradas. Nesse sentido, a percepção do que sejam essas emoções variam no espaço-tempo. Para os padrões ocidentais, as relações narradas por Amélie, provoca uma série de pathemias (indignação, revolta, fúria, tristeza, decepção, horror) que muito provavelmente não encontram respaldo na sociedade japonesa.

\section{Orientalismo e estereótipos}

Stupeur et tremblements conta a história de choques culturais vivenciados pela personagem que vive conflitos identitários. A narrativa de Nothomb é composta de dicotomias opositivas estereotipadas a respeito do modo de ser dos orientais e dos ocidentais. Essa problemática remete-nos ao conceito de orientalismo forjada por Said (2007).

Para Said, o orientalismo é uma construção discursiva, uma ideologia de controle, ou melhor, uma invenção do Ocidente imperialista cujo objeto de estudo é o Oriente, e cujo pretexto é instituir visões de atraso, incompletude e inferioridade dos povos do Oriente. Nesse sentido, o orientalismo, é responsável pelo perpetuar de estereótipos, pensamentos forjados para dominar,

\footnotetext{
${ }^{13}$ Enverguei, portanto, a máscara do estupor e comecei a tremer. Mergulhei um olhar cheio de medo no daquela jovem, $e$ gaguejei [...] (NOTHOMB, 2001, p. 130 - Tradução de Clóvis Marques)
}

Gláuks: Revista de Letras e Artes - jan/jun. 2019 - Vol. 19, $N^{o} 1$ 
reestruturar e exercer o poder sobre o Outro, um conjunto de ideias circunscritas a valores apresentados de modo generalizado (SAID, 2007).

Vê-se que que o conceito de orientalismo está fortemente atrelado ao de estereótipo, ao de senso comum, às ideias pré-concebidas que se tem do Outro. Os estereótipos são, em linhas gerais, imagens cristalizadas pelos sujeitos que as gerenciam em seu meio social graças a mecanismos ideológicos. Essas imagens têm o poder de determinar, em graus variados, a maneira de pensar, de sentir e de agir dos indivíduos. Os estereótipos são, pois, uma espécie de ponte na relação do sujeito com o mundo, com o real, com o Outro e consigo mesmo. Vale registrar que cada época conta com seus estereótipos, assim como cada grupo social constrói coletivamente uma gama de saberes comuns partilhados. Desse modo, as representações são discursos sociais que se configuram como saberes, como crenças e como valores, os quais conferem identidade coletiva a um grupo social e permitem aos membros desse grupo construírem uma consciência de si e do outro. (AMOSSY, 1991; AMOSSY \& PIERROT, 2011)

Seguindo os entendimentos supracitados, temos que Stupeur et tremblements é a espetacularização da estereotipia, do orientalismo. Em um universo repleto de (falsas) dicotomias opositivas entre Ocidente e Oriente, entre Bélgica e Japão e suas respectivas culturas, Amélie vive seu drama cotidiano. Por um lado, a cultura japonesa, com suas regras sociais rígidas para o padrão ocidental, europeu, impactando na vida pessoal e profissional da personagem, que sofre por não conseguir corresponder ao padrão vigente. Por outro lado, as personagens nipônicas, que veem Amélie de forma também estereotipada, como cidadã ocidental incapaz de se adequar a cultura oriental. Assim, no nível intradiegético, há toda uma dramatização a respeito das formas estereotipadas de ver o outro e, por conseguinte, de ver a si próprio, visto o dualismo opositivo da constituição dos sujeitos (eu-tu, eu-ele), todos construindo seus ethé, pelo logos, de forma pathêmica.

A narradora-personagem descreve sua visão ocidental a respeito da mulher nipônica e discute os direitos e deveres da mulher na sociedade japonesa. Fubuki torna-se a representação estereotipada da mulher japonesa moderna:

Gláuks: Revista de Letras e Artes - jan/jun. 2019 - Vol. 19, $N^{o} 1$ 
[...] s'il faut admirer la Japonaise - et il le faut - c'est parce qu'elle ne se suicide pas. On conspire contre son idéal depuis sa plus tendre enfance. On lui coule du plâtre à l'intérieur du cerveau [...] Car, en fin de compte, ce qui est assassiné à la Nippone à travers ces dogmes incongrus, c'est qu'il ne faut rien espérer de beau. N'espère pas jouir, car ton plaisir t'anéantirait. N'espère pas être amoureuse, car tu n'en vaux pas la peine : ceux qui t'aimeraient, t'aimeraient pour tes mirages, jamais pour ta vérité. N'espère pas que ta vie t'apporte quoi que ce soit, car chaque année qui passera t'enlèvera quelque chose. N'espère même pas une chose aussi simple que le calme, car tu n'as aucune raison d'être tranquille. Espère travailler. Il y a peu de chances, vu ton sexe, que tu t'élèves beaucoup, mais espère servir ton entreprise. (NOTHOMB, 1999, p. 93-94) $)^{14}$

Do excerto acima, vemos que a autora registra uma visão socialmente partilhada segundo a qual o sistema social no Japão é castrador e autoritário, que subjuga a mulher a espaços inferiores durante toda sua vida. Amélie toca em temas conhecidos no que tange o senso comum sobre o Japão como o suicídio e o trabalho, por exemplo. De maneira clichê, a mulher japonesa é vista como aquela que, oprimida, não pode esperar muito da vida e tampouco querer conquistar uma série de elementos considerados básicos para os ocidentais tais como o amor, o reconhecimento pelo seu trabalho, a liberdade de escolha e os prazeres, sejam sexuais, sociais ou profissionais.

Ainda que a autora se considere mais japonesa que belga, ela, paradoxalmente, parte de sua perspectiva ocidental para narrar, criticar e julgar o modo de ser dos orientais, baseada em um conjunto de estereotipias que definem a identidade das mulheres e dos homens japoneses em contraponto com a identidade das mulheres e dos homens do ocidente. Tem-se a impressão de que as condições das mulheres orientais são diferentes (inferiores) das ocidentais. Sabemos, no entanto, que isso não representa a verdade dos fatos. Tanto no Oriente quanto no Ocidente, as mulheres são, em sua maioria, subjugadas, oprimidas, desvalorizadas, humilhadas e agredidas, prova de que a descrição da mulher japonesa feita por Nothomb é construída sobre falsas ideias pré-concebidas sobre o Oriente. Lá assim como cá, as mulheres são recorrentemente adjetivadas

\footnotetext{
${ }^{14}$ [...] se devemos admirar a japonesa - e efetivamente devemos - é porque ela não se suicida. Seu ideal é alvo de conspiração desde a mais tenra infância. O interior do seu cérebro é banhado em gesso [...]. Pois, no fim das contas, o que se está dizendo à japonesa através desses dogmas absurdos é que não deve esperar nada de belo. Não esperes gozar, pois teu prazer te aniquilaria. Não esperes apaixonar-te, pois não vales a pena: os que viessem a te amar te amariam por tuas miragens, e nunca pela tua verdade. Não esperes que a vida te proporcione o que quer que seja, pois, cada ano que passar te tirará algo, não tens qualquer motivo para sentir-se tranquila. Espere trabalhar. São poucas as chances, dado o teu sexo, de que te eleves muito, mas espere servir tua empresa. (NOTHOMB, 2001, p. 70-71 - Tradução de Clóvis Marques)
}

Gláuks: Revista de Letras e Artes - jan/jun. 2019 - Vol. 19, $N^{o} 1$ 
como "putas", "vacas", “imundas", "vulgares" e “incompetentes", palavras carregadas de preconceitos pathemizantes atribuídas, de maneira sexista, às mulheres:

Si à vingt-cinq ans tu n'es pas mariée, tu auras de bonnes raisons d'avoir honte [...] si tu ris, tu ne seras pas distinguée $[\ldots]$ si ton visage exprime un sentiment, tu es vulgaire $[\ldots]$ si tu mentionnes l'existence d'un poil sur ton corps, tu es immonde [...] si un garçon t'embrasse sur la joue en public, tu es une putain [...] si tu manges avec plaisir, tu es une truie $[\ldots]$ si tu éprouves du plaisir à dormir, tu es une vache. (NOTHOMB, 1999, p. 93$94)^{15}$

Para Nothomb, esses dogmas orientais impedem o desenvolvimento de uma personalidade individual e ignoram as necessidades básicas das cidadãs japonesas. Ela deixa subtendido, que esse engessamento é símbolo de uma sociedade ideologicamente decadente e atrasada, segundo parâmetros ocidentais. As funções da mulher na sociedade nipônica parecem muito bem definidas e pouco flexíveis. As regras são extensas e cruéis, não lhes permitindo qualquer deslize, qualquer desobediência. Amélie ainda vai além na lista das exigências que recaem sobre as mulheres e descreve situações, como a do controle de necessidades fisiológicas, para mostrar o quanto esses deveres são absurdos:

Par exemple, même quand tu seras isolée aux toilettes pour l'humble besoin de soulager ta vessie, tu auras l'obligation de veiller à ce que personne ne puisse entendre la chansonnette de ton ruisseau : tu devras donc tirer la chasse sans trêve. [...] Tu as faim ? Mange à peine, car tu dois rester mince, non pas pour le plaisir de voir les gens se retourner sur ta silhouette dans la rue - ils ne le feront pas -, mais parce qu'il est honteux d'avoir des rondeurs. (NOTHOMB, 1999, p. 95)

Dessa forma, não há trégua para a mulher que pretende (e precisa) ser irrepreensível, visto que há apenas restrições e proibições:

\footnotetext{
${ }^{15}$ Se não estiveres casada aos vinte e cinco anos, terás mesmo bons motivos para te envergonhares [...] se rires, não terás classe [...] se teu rosto exprime um sentimento, és vulgar [...] se mencionares a existência de um pêlo em teu corpo, és imunda [...] se um rapaz te beijar no rosto em público, és uma puta [...] se comeres com prazer, és uma porca [...] se sentires prazer em dormir, és uma vaca. (NOTHOMB, 2001, p. 70-71 - Tradução de Clóvis Marques)

16 Por exemplo, mesmo quando estiveres isolada no banheiro para a humilde necessidade de aliviar tua bexiga, terás a obrigação de cuidar para que ninguém venha a ouvir a musiquinha de teu riacho: terás, portanto, de puxar a válvula de descarga sem descanso. [...] Tens fome? Come pouco, pois deves permanecer esbelta, não pelo prazer de ver as pessoas se voltarem para tua silhueta na rua - o que não ocorrerá -, mas porque é vergonhoso ser roliça. (NOTHOMB, 2001, p. 72 Tradução de Clóvis Marques)
}

Gláuks: Revista de Letras e Artes - jan/jun. 2019 - Vol. 19, $N^{o} 1$ 
Nombre d'entre elles (les Japonaises) se sont révoltées et tu te révolteras peut-être pendant la seule période libre de ta vie, entre dix-huit et vingt-cinq ans. Mais à vingtcinq ans, tu t'apercevras soudain que tu n'es pas mariée et tu auras honte. (NOTHOMB, 1999 , p. 98$)^{17}$

Retomando Said (2007), percebemos que toda essa construção ethótica da mulher, mais particularmente da mulher oriental, é uma construção discursiva ideologicamente (de)marcada pelo Ocidente, "apenas” uma leitura parcial, estereotipada. Não nos é possível julgar o Oriente, seus hábitos, a forma como tratam as mulheres com nossas ferramentas ideológicas. Não podemos medir o outro com a nossa "régua". Há que se respeitar as diferenças e relativizar as verdades, os modos de vida e, sobretudo, tomar cuidado com os estereótipos ao construir o ethos do outro.

\section{Considerações Finais}

Para Nothomb, fazer literatura demonstra ser uma forma de recordar, de presentificar o passado. Além disso, escrever uma autoficção é buscar dar forma à sua identidade, delinear seu ethos. Dividida entre a nacionalidade belga e a japonesa, Amélie escreve em francês para falar de suas memórias nipônicas, e levar ao seu leitor uma história carregada de emoções, com o objetivo de pathemizá-lo. Nesse sentido, sua escrita é uma espécie de linha com a qual ela tece sua biografia. Ao narrar sobre suas experiências de vida no Japão, a escritora constrói, de maneira dicotomicamente opositiva, não apenas imagens de si, como também do Oriente.

Stupeur et tremblements é, segundo David (2006), um desabafo, uma fuga do passado, a construção da sua imagem, da sua identidade: "Nothomb: témoigne de l'acharnement qui lui a été nécessaire pour se (re)construire une image et un corps qui tiennent le coup, dont l'objet-livre devient le support."18 (2006, p. 16). Sob o ponto de vista argumentativo, Nothomb se vale daquilo que Barthes (2004) chama de efeito de real para poder convencer seus leitores, com uma retórica

\footnotetext{
${ }^{17}$ Muitas deles (as japonesas) revoltaram-se e talvez venhas também a revoltar-se durante o único período livre de sua vida, entre dezoito e vinte e cinco anos. Mas aos vinte e cinco anos te haverás de dar conta subitamente de que não estás casada, e sentirás vergonha. (NOTHOMB, 2001, p. 74 - Tradução de Clóvis Marques)

${ }^{18}$ Tradução livre: Nothomb: testemunha a obstinação que foi the necessária para (re)construir uma imagem e um corpo que aguentam o abalo, cujo livro-objeto torna-se o suporte.
}

Gláuks: Revista de Letras e Artes - jan/jun. 2019 - Vol. 19, $N^{o} 1$ 
aristotélica, de que a sociedade japonesa e a autora-narradora-personagem são exatamente aquilo que é descrito. A veracidade do narrado é atestada pela autora em entrevistas, o que dá maior credibilidade à ficção.

Stupeur et tremblements torna-se um instrumento ideológico poderoso, ao mostrar, oposições culturais entre o Ocidente e o Oriente. Sendo uma mulher branca, ocidental, europeia, belga e falante da língua francesa, Nothomb (e também sua narradora-personagem) representa um etnocentrismo frente ao Oriente, ao Japão, à língua e à cultura nipônica. Essa estrutura narrativa leva, evidentemente, a repercussões e consequências nacionalistas. Conforme assevera a própria autora, esse romance provocou e ainda provoca mal-estar em seus leitores orientais, que, muitas vezes, a consideram persona non-grata:

[...] depuis la parution de Stupeur, chaque fois que j'ai affaire à des Japonais je sens qu'on me demande de m'expliquer. Je n'ai pas envie de m'expliquer. [...] J'ai eu affaire à quelques journalistes japonais, et ça s'est très mal passé. C'était des interviews qui ressemblaient à des interrogatoires de police. Alors ça m'a vraiment dégoûtée. [...] Je sais très bien qu'ils veulent réussir à me faire dire la fameuse phrase, à savoir 'Ce n'est pas vraiment ce que je voulais écrire' alors que c'était vraiment ce que je voulais écrire. Ils ont gardé une autorité mentale sur moi... j'ai du mal à leur résister. [...] Il y a eu des réactions très négatives des chefs d'entreprises, mais aussi des réactions positives de petits employés ou de gens comme ça. J'ai eu aussi des relations épistolaires avec des Japonais francophones qui ont pu parler du livre de façon très intelligente. (NOTHOMB apud LEE, 2004, p. 571) ${ }^{19}$

Essa entrevista nos permite afirmar, juntamente com Amanieux (2005), que Amélie cumpre, no conjunto de sua obra, independentemente de seu gênero, o objetivo esperado de qualquer obra literária, qual seja, o de agregar o ethos daquele que escreve e de tocar o leitor com palavras pathemizadas e pathemizantes: “[...] drôles, semés d'humour noir, cyniques, exagérés, morbides, excentriques, abominables, attirants, étranges, irréels, surréalistes, provocateurs et non conformistes. ${ }^{.20}(2005$, p. 34)

\footnotetext{
${ }^{19}$ Tradução livre: [...] desde o lançamento de Stupeur, toda vez que lido com japoneses sinto que me pedem para me explicar. Eu não quero me explicar. [...] Tive que lidar com alguns jornalistas japoneses, e tudo ocorreu muito mal. Foram entrevistas que pareciam interrogatórios policiais. Então isso realmente me enojou. Além disso, eles são muito fortes e em relação a eles, eu sou muito fraca. Eu sei muito bem que eles querem me fazer dizer a famosa frase: 'Não era realmente isso o que eu queria escrever', quando era sim realmente isso o que eu queria escrever. Eles mantiveram uma autoridade mental sobre mim ... Eu não posso resistir a eles. [...] Houve reações muito negativas de líderes empresariais, mas também reações positivas de pequenos funcionários ou pessoas assim. Tive também relações epistolares com japoneses francófonos que puderam falar sobre o livro de uma maneira muito inteligente.

20 Tradução livre: [...] engraçados, semeados de humor negro, cínicos, exagerados, mórbidos, excêntricos, abomináveis, atraentes, estranhos, irreais, surrealistas, provocadores e inconformistas.
}

Gláuks: Revista de Letras e Artes - jan/jun. 2019 - Vol. 19, $N^{o} 1$ 


\section{Referências Bibliográficas}

AHL, N. C. Entretien avec Amélie Nothomb : « On n'est pas maître, on subit la langue ». Le Monde, 2013. (disponible en : https://bit.ly/325aNOT - accédé le 30 mars 2019)

AMANIEUX, L. Amélie Nothomb, l'éternelle affamée, Paris : Albin Michel, 2005.

AMOSSY, R. "Stereotypes and Representation” In Fiction - Poetics Today, n. 5. 1984, p. 689700 . Les idées reçues : sémiologie du stéréotype. Paris : Nathan. 1991.

(org.) Images de soi dans le discours : la construction de l'ethos. Genève : Delachaux et Niestlé, 1999. 2010.

. La présentation de soi: Ethos et identité verbale. Paris : Presses Universitaires de France,

AMOSSY, R. \& PIERROT, A. H. Stéréotypes et clichés: Langue, discours, société. Paris: Armand Colin, 2011.

ARISTÓTELES. Retórica. Lisboa: Casa da Moeda, 2005.

BAKTHIN, M. Estética da Criação Verbal. São Paulo: Martins Fontes, 2010.

BARTHES, R. “A retórica antiga". In: Pesquisas de Retórica. Petrópolis: Ed. Vozes, 1975, p. 147-221.

. “O efeito de real”. In: O rumor da língua. São Paulo: Martins Fontes, 2004.

CHARAUDEAU, Patrick. Langage et Discours: éléments de sémiolinguistique. Paris: Hachette, 1983.

. «La pathémisation à la télévision comme stratégie d'authenticité » In : PLANTIN, C. et al. (orgs.) Les émotions dans les interactions. Lyon : Presses Universitaires de Lyon. 2000.

. Les stéréotypes, c'est bien. Les imaginaires, c'est mieux. In : BOYER, H. Stéréotypage, stéréotypes : fonctionnements ordinaires et mises en scène. Paris : L'Harmattan. 2007, p. 49-63.

. « Pathos et discours politique » In : RINN, M. (org.) Émotions et Discours : l'usage des passions dans la langue. Rennes: Presses Universitaires de Rennes. 2008, p. 49-58.

Charaudeau, P., MAingueneau, D. Dicionário de Análise do Discurso. São Paulo:

Gláuks: Revista de Letras e Artes - jan/jun. 2019 - Vol. 19, $N^{o} 1$ 
Contexto, 2004.

DAVID, M. Amélie Nothomb : Le symptôme graphomane. Paris : L'Harmattan, 2006.

DEWEZ, N. Fiche de lecture : Stupeur et tremblements, d'Amélie Nothomb. Le petit littéraire, 2013.

DOUBROVSKY, S. Fils. Paris : Folio, 1977.

ELSTER, J. « Rationalité, émotions et normes sociales » In: PAPERMAN, P., OGIEN, R. (orgs.) La couleur des pensées: sentiments, émotions, intentions. Paris: École des Hautes Études en Sciences Sociales. 1995, p. 33-64.

GRELL, I. L'autofiction. Paris : Armand Colin, 2014.

GRINFAS, J. Interview avec Amélie Nothomb et Sylvie Testud sur Stupeur et Tremblements. 2007. Disponível em: https://bit.ly/32but3A (Consulté le 2 mars 2018)

JOWA, E., MERTENS, E. Le Vif, L'Express: entretien avec Amélie Nothomb. 2001.

LEE, M. D. «Entretien avec Amélie Nothomb ». The French Review. Vol. 77, No. 3, 2004, p. $562-575$.

LEJEUNE, P. Le pacte autobiographique. Essais : Paris, 1996.

MAINGUENEAU, D. O contexto da obra literária. São Paulo: Martins Fontes, 2001a. . Elementos de linguística para o texto literário. São Paulo: Martins Fontes, 2001b.

. "Ethos, cenografia, incorporação" In: AMOSSY, R. (org.) Imagens de si no discurso: a construção do ethos. São Paulo: Contexto, 2005, p. 69-92.

. Discurso Literário. São Paulo, Contexto, 2006.

. "A propósito do ethos" In: MOTTA, A. R. \& SALGADO, L. (orgs.) Ethos Discursivo. São Paulo: Contexto, 2008, p. 11-29.

. "Ethos literário, ethos publicitário e apresentação de si" In: MACHADO, I. \& MELLO, R. (orgs.). Análises do Discurso Hoje. Vol. 3. Rio de Janeiro: Nova Fronteira, 2010, p. 193-207.

NARJOUX, C. Étude sur Stupeur et tremblements, d'Amélie Nothomb. Paris: Ellipses, 2004

NOTHOMB, A. Hygiène de l'Assassin. Paris : Albin Michel, 1992.

Gláuks: Revista de Letras e Artes - jan/jun. 2019 - Vol. 19, $N^{o} 1$ 
. Le sabotage amoureux. Paris : Albin Michel, 1993.

. Stupeur et tremblements. Paris : Albin Michel, 1999.

. Temor e Tremor. Lisboa: Editorial Bizânico, 2000a.

. Métaphysique des tubes. Paris : Albin Michel, 2000b.

. Medo e submissão. Rio de Janeiro: Record. 2001.

. Antéchrista. Paris : Albin Michel, 2003.

. Ni d'Ève ni d'Adam. Paris : Albin Michel, 2007.

.Une forme de vie. Paris : Albin Michel, 2010.

. La nostalgie heureuse. Paris : Albin Michel, 2013.

PLANTIN, C. Les bonnes raisons des émotions : principes et méthode pour l'étude du discours émotionné. Bern : Peter Lang, 2011.

SAGALYN, A. Le Club reçoit Amélie Nothomb. Interview du 05 septembre 2000.

SAID, E. Orientalismo: o Oriente como invenção do Ocidente. São Paulo: Companhia das Letras, 2007.

SAVIGNEAU, J. Écrire, écrire, pourquoi ? Amélie Nothomb: Interview. Éditions de la Bibliothèque Publique d'Information, 2009, p. 3-24.

STETENFELD, N. Analyse d'œuvre : Stupeur et Tremblements, d'Amélie Nothomb. Bruxelles : Profil Littéraire, 2017. 


\title{
Images of self and emotions in Stupeur et Tremblements, by Amelie Nothomb
}

\begin{abstract}
This work aims to investigate the textual and discursive structure of a specific literary work of the Belgian writer Amélie Nothomb, namely, Stupeur et tremblements [Fear and Trembling], published in 1999. In order to achieve this objective, we selected, as theoretical basis, studies from Discourse Analysis and its convergence with Argumentation and Rhetoric. At this articulation, we are mainly concerned with the analytical categories such as genre, ethos, pathos and stereotype. With this theoretical knowledge, we can discuss the problematic that involves that book, which is considered a novel, an autofiction or even an autobiography at the same time. In genres such as those, the concept of ethos becomes an important key, due to the emphasis of the narrative that lies on the identities of the author, the narrator and the main character. Like any literary enunciation, Nothomb's book seeks to touch its readers. For this reason, the concept of pathos helps us in the studies not only of the emotions in(side) the novel, but also of those focused on the instituted reader. Finally, the notion of stereotype, linked to notions of belief and socio-discursive imaginaries, allows us to better contextualize the work in its space-time.
\end{abstract}

Keywords: Amélie Nothomb, Stupeur et tremblements, self-image, emotions, Discourse Analysis. 